\title{
ISOKINETIC TORQUE PEAK AND HAMSTRINGS/ QUADRICEPS RATIOS IN ENDURANCE ATHLETES WITH ANTERIOR CRUCIATE LIGAMENT LAXITY
}

Eliane Magaieski Portes, Leslie Andrews Portes, Viviane Gomes Botelho, Sérgio de Souza Pinto

Portes EM, Portes LA, Botelho VG, Pinto S de S. Isokinetic torque peak and hamstrings/quadriceps ratios in endurance athletes with anterior cruciate ligament laxity. Clinics. 2007;62(2):127-32.

PURPOSE: To evaluate torque and the hamstring/quadriceps ratio of the knee of athletes with and without anterior cruciate ligament laxity.

METHODS: Twenty-eight male athletes, 19 without anterior cruciate ligament laxity and 9 with anterior cruciate ligament laxity, were evaluated with an isokinetic machine model Cybex 770. The peak torque of quadriceps and hamstrings was compared, and the hamstring/quadriceps ratio on the constant angular speed of $60^{\circ}$ per second were also compared.

RESULTS: In athletes with anterior cruciate ligament laxity, the peak torque values (right and left knees) of flexors (120 \pm 15 and $116 \pm 15 \mathrm{Nm})$ and of extensors $(218 \pm 36 \mathrm{Nm}$ and $207 \pm 26 \mathrm{Nm})$ were not different than those of athletes without laxity $(109 \pm 21$ $\mathrm{Nm}$ and $111 \pm 22 \mathrm{Nm} ; 191 \pm 5 \mathrm{Nm}$ and $188 \pm 35 \mathrm{Nm}$ ). The hamstring/quadriceps ratio of athletes with laxity (right: $57 \pm 6 \%$ and left: $56 \pm 8 \%$ ) did not differ from those without anterior cruciate ligament laxity (right: $58 \pm 9 \%$ and left: $58 \pm 7 \%$ ).

CONCLUSIONS: The anterior cruciate ligament laxity of long distances running athletes did not significantly alter the peak torque of flexors and of extensors or the hamstring/quadriceps ratio.

KEYWORDS: Isokinetic torque. Knee. Anterior cruciate ligament. Laxity. Athletes.

\section{INTRODUCTION}

Torque is the rotational effect of force generated by a single muscle or group of muscles in relation to the considered joint. ${ }^{1}$ Because the term force is basically a linear entity, in this study when referring to muscle strength, the term torque was conventionally used. The term strength refers to the tension that a muscle or group of muscles exerts against a determined resistance. ${ }^{2}$ The unbalanced condition of strength and the hypotrophy of the flexor and extensor muscles of the knee joint are muscle malfunction-

Physiotherapy Clinic, Universidade Cidade de São Paulo (UNICID) - São Paulo/SP, Brazil.

Exercise physiology Laboratory, Centro Universitário Adventista de São Paulo (UNASP) - São Paulo/SP, Brazil.

Email: leslie.portes@unasp.edu.br

Received for publication on July 07, 2006.

Accepted for publication on November 14, 2006. causing factors that alter joint stability, predisposing athletes to injury. ${ }^{3-5}$

The muscular torque of the quadriceps and hamstrings, as well as their torque ratio (H/Q), is usually evaluated by the isokinetic test. ${ }^{6}$ The H/Q ratio is used both clinically and in the laboratory as an indicator of the strength balance between the knee joint muscles. ${ }^{7}$ The H/Q ratio is conventionally calculated by dividing the maximum values of the flexion by the maximum values of the extension of the knee joint in angled speed and determined contraction modes. ${ }^{8}$

It is difficult to determine whether the hamstring weakness, the quadriceps weakness, or both are related to the knee injuries, or if muscle weakness is a consequence of the injury. ${ }^{9}$ Evidence suggests that highly developed quadriceps muscles contribute to a decrease of the co-activation of the hamstring antagonists, thus increasing the susceptibility for anterior cruciate ligament injury. ${ }^{10}$ 
The anterior cruciate ligament (ACL) is the primary ligament that limits the anterior translation of the tibia in relation to the femur. Subjects with ACL injury demonstrate laxity, an increase in tibia translation, and knee instability. ${ }^{11}$ In ACL-injured athletes, the H/Q ratio $(r=0.63)$ correlated significantly $(P<0.001)$ with the functional capacity of the ACL of injured knees. ${ }^{12}$ The measurement of ACL laxity is clinically important from the point of view of preventive diagnosis of knee injury as well as for comparison of pre- and postsurgical reconstruction and/or conservative treatment. Generalized articular laxity can also be a risk factor for a number of skeletal muscle injuries. ${ }^{13}$

Well-known clinical tests like the Lachman test, the anterior drawer test, and pivot shift are used to determine injury and laxity of the ACL. Of these, the Lachman test is often considered the most sensitive and reliable, ${ }^{14}$ and it produces similar results to those of the radiological Lachman test. ${ }^{11}$ However, due to its subjectivity, the results may vary among the examiners. Despite the technological advances in knee injury diagnosis, careful evaluation of the patient history and complete physical examination continue to be the fundamental basis of knee injury evaluation. Thus, the adequately performed Lachman test is the simplest and most accessible test in the administration of physiotherapy for the evaluation of nonprofessional athletes. It has been shown that ligament laxity increases the risk for injuries in professional rugby ${ }^{15}$ and soccer athletes, ${ }^{16,17}$ though little is known about endurance runners and amateur athletes. The objective of this research was to evaluate the ACL laxity of endurance runners and to investigate the H/Q ratio after isokinetic strength test in athletes with and without ACL laxity. Our hypothesis was that endurance-running athletes with ACL laxity have torque alterations in the knee joint muscles.

\section{METHODS}

\section{Sample}

Endurance-running athletes (5000 meters and over) were invited to participate in the study so long as they fitted the following criteria: a) male adult age 20 and above; b) over 2 years of coach-supervised sport practice; c) practicing more than 5 days a week; d) national and international competition participation; e) absence of functional limitation in both knees; f) absence of ACL injury in one or both knees; and g) not having performed thigh muscle strengthening exercises in the last 6 months. From the 52 athletes who positively answered the invitation, 28 were eligible for the study. The sample characteristics were the following: age, $33.4 \pm 8.9$ years; height, $171.9 \pm 7.3 \mathrm{~cm}$; weight, $65.6 \pm 7.3 \mathrm{~kg}$; body fat percentage, $8.5 \pm 4.2 \%$; and maximum oxygen consumption $\left(\mathrm{VO}_{2} \max \right), 61.2 \pm 4.7$ $\mathrm{mL} / \mathrm{kg} / \mathrm{min}$. The athletes had been training for $9.5 \pm 8.1$ years, $6.8 \pm 0.5$ days a week, and $1.3 \pm 0.4$ sessions a day. They ran $14.6 \pm 4.9 \mathrm{~km} / \mathrm{day}, 91.6 \pm 32.7 \mathrm{~km} /$ week.

After being fully informed about the procedures of the study, those who wished to participate signed the adequate informed consent form.

The research was approved by the ethics committees of the involved institutions.

After the knee exams, the athletes were divided into 2 groups: G1, ACL laxity-free athletes; and G2, athletes who had ACL laxity in at least 1 of their knees.

\section{Anthropometric and fitness measures}

The athletes were instructed not to exhaustively train on the day before the evaluations. All had to attend each evaluation fed, hydrated, and suitably dressed. The anthropometric measures were acquired according to the described protocol. ${ }^{18,19}$ Summarizing, height was measured by using a stadiometer, and total body weight was measured on a digital Fillizola scale. A Harpenden skinfold caliper model was used for the 7 skinfold measurements (7DC) as follows: triceps (TR), subscapular (SE), thoracic (TO), axillar (AX), iliac (SI), abdominal (AB), thigh (TH), and calf (CA). Every subcutaneous fold was measured 3 times, and the median was used for the calculations. The body fat percentage $(\% \mathrm{G})$ was estimated using the Siri equation $(\% \mathrm{G}$ $=(495 / \mathrm{D})-450)$ starting from the body density $(\mathrm{D}=1.112$ $-(0.00043499 \times 7 D C)+\left(0.00000055 \times\left(7 D^{2}\right)\right)-$ $(0.00028826 \mathrm{x}$ age $)$. From $\% \mathrm{G}$, the lean mass of every athlete was calculated. The maximum oxygen consumption $\left(\mathrm{VO}_{2}\right.$ max) was estimated using the Bruce protocol (treadmill maximum test), using the following equation: $\mathrm{VO}_{2}$ max $(\mathrm{mL} / \mathrm{kg} / \mathrm{min})=14.76-(1.379 \times \mathrm{T})+\left(0.451 \times \mathrm{T}^{2}\right)-(0.012$ $\left.\mathrm{x} \mathrm{T}^{3}\right)$. The test time $(\mathrm{T})$ was approximated to every fourth of a minute. ${ }^{20}$

\section{Knee Evaluation}

The specific Lachman and anterior drawer tests were performed to evaluate right and left knee ligament laxity. ${ }^{14,21,22}$ The Lachman test ${ }^{14,22}$ was performed having the patient in a supine position with a $30^{\circ}$ knee contraction. A cylindrical cushion was put under the fossa poplitea so that the hamstring muscles could be relaxed. One of the examiner's hands was placed on the distal lateral aspect of the femur, while the other hand was placed on the proximal medial aspect of the tibia. The hand that was placed on the distal femur was used to stabilize it, and the hand placed 
on the tibia was used to perform an anterior tibia translation movement. The laxity-free ACL knee must be firm at the end of the execution of the strength movement, ie, no translation must be detected. The knee that demonstrates ACL laxity shows a tibia translation in relation to the femur. This translation movement is perceived by feeling a smooth motion at the end of the whole process.

The anterior drawer test ${ }^{22}$ was performed having the patient in the supine position with a $45^{\circ}$ hip flexion, a $90^{\circ}$ knee flexion, and both feet on the table. The integrity of 3 ACL bundles was tested. In every phase of the test, the patient's feet were positioned in 3 distinct positions: neutral, inversion, and eversion. The examiner positioned the patient's foot, and his hands were put around the patient's knee, having his thumbs on the medium lateral articular lines. Then the anterior tibia traction was performed. The test was considered to be positive when an anterior translation of the tibia was perceived, indicating ACL laxity. All tests were performed by the same examiner.

\section{Articular hypermobility evaluation}

The articular hypermobility was evaluated only in the G2 athletes according to the method developed by Cartes and Wilkinson (1964), which was modified by Beighton and Horan (1969). ${ }^{13,23}$ The following tests were performed on both sides: passive hyperextension of the little finger $>$ $90^{\circ}$, passive apposition of the thumb to the flexor aspect of the forearm, hyperextension of the elbow $>10^{\circ}$, hyperextension of the knee $>10^{\circ}$, and anterior trunk flexion with both knees extended in a way that the palms of both hands touched the floor. The number of positive occurrences was converted into a score with a 9 to 0 range. Scores were classified as follows: 0 through 2 , normal physiological findings; 3 or 4, a little articular hypermobility; 5 through 9, severe articular hypermobility. ${ }^{23}$

\section{Isokinetic evaluation}

The isokinetic torque of the hamstrings and quadriceps was determined bilaterally at a speed of $60 \%$ sy using a Cybex isokinetic dynamometer (model 770). The concentric flexion extension knee protocol was also used. ${ }^{4}$ The athletes performed a 5-minute warm up on a cycloergometer (model Kikos JPC 5100) with no load and at a $50 \mathrm{rpm}$ rhythm. After that, the athletes performed stretching exercises for the flexor and extensor muscles of both knees. The knee evaluation order was random. The test was performed having the subjects seated, fastened around their thorax, waist, and thigh, and their hands were laid on the arms of the armchair. The athletes were positioned in a $90^{\circ}$ hip flexion. The knee joint articulation axis was aligned to the dynamometer mechanic arm lever axis. The length of the dynamometer arm, which was fastened to the distal portion of the tibia by a Velcro strap, was adapted according to the length of the leg of the athlete. The gravity force was corrected by the intrinsic device of the dynamometer. The participants were properly instructed about the test that was performed in 2 stages: first, 3 submaximum repetitions so that the subjects could get acquainted with the equipment; second, 3 maximum repetitions to determine the peak torque $(\mathrm{Nm})$. The display of the equipment was placed in a such a way as to allowe the athletes to see it, and verbal encouragement was given during the test performance. The equipment was calibrated regularly every 4 tests and operated by the same evaluator. The evaluated parameters were peak torques (PT in Nm) of the flexor and extensor muscles of the knee joint and the torque H/Q ratio. All of the values obtained correspond to concentric contraction.

\section{Statistical analysis}

The results are shown as mean \pm standard deviation (SD). The athletes' anthropometric, fitness, torque, and the $\mathrm{H} / \mathrm{Q}$ ratio values were analyzed by the Student $t$ test. The comparison between the right and left knees was made by the paired $t$ test. The level of significance was 0.05 .

\section{RESULTS}

Out of the 28 evaluated athletes, 19 did not exhibit ACL laxity (G1) while 9 did (G2). The anthropometric and physical aptitude characteristics from both groups are summarized in Table 1.

Table 1 - Anthropometric characteristics of the long distance-running athletes with and without anterior cruciate ligament laxity

\begin{tabular}{llll}
\hline Variables & G1 & G2 & Significance \\
\hline Age (years) & $34.1 \pm 8.6$ & $32.0 \pm 9.9$ & NS \\
Height $(\mathrm{cm})$ & $169.3 \pm 5.8$ & $177.6 \pm 7.3$ & $P=0.003$ \\
Weight $(\mathrm{kg})$ & $64.1 \pm 7.7$ & $68.8 \pm 5.4$ & $\mathrm{NS}$ \\
Body fat percentage (\%) & $8.6 \pm 4.2$ & $8.1 \pm 4.3$ & $\mathrm{NS}$ \\
Lean mass (kg) & $59.1 \pm 6.0$ & $63.6 \pm 4.8$ & $\mathrm{NS}$ \\
VO, max (mL/kg/min) & $61.0 \pm 4.7$ & $61.5 \pm 5.1$ & $\mathrm{NS}$ \\
Average competition speed & $4.9 \pm 0.4$ & $4.9 \pm 0.4$ & $\mathrm{NS}$ \\
(m/s) & & & \\
Years of training & $8.2 \pm 6.5$ & $12.2 \pm 10.1$ & $\mathrm{NS}$ \\
Weekly training frequency & $6.7 \pm 0.5$ & $6.8 \pm 0.4$ & $\mathrm{NS}$ \\
(days) & & & \\
Daily running distance $(\mathrm{km})$ & $15.0 \pm 5.5$ & $14.0 \pm 3.5$ & $\mathrm{NS}$ \\
\hline
\end{tabular}

NS: no significant differences between groups ( $P>0.05)$; G1: long distancerunning athletes without anterior cruciate ligament (ACL) laxity; G2: long distance-running athletes with anterior cruciate ligament (ACL) laxity 
The age, weight, body fat percentage $(\% \mathrm{G})$, lean mass, $\mathrm{VO}_{2}$ max, average competition speed, years of training, weekly practice frequency, and daily running distance did not differ in G1 and G2. Only the height values from the G2 athletes were significantly higher than those from the G1 athletes $(P=0.003)$.

Among the 9 athletes with ACL laxity, only 1 scored 4 in the Beighton scale, indicating little articular hypermobility. Table 2 shows the results for the isokinetic strength test.

Table 2 - Isokinetic strength comparison between the athletes with and without anterior cruciate ligament laxity

\begin{tabular}{llll}
\hline Variables & G1 & G2 & Significance \\
\hline Right knee flexion $(\mathrm{Nm})$ & $109 \pm 21$ & $120 \pm 15$ & NS \\
Left knee flexion $(\mathrm{Nm})$ & $111 \pm 22$ & $116 \pm 15$ & NS \\
Right knee extension $(\mathrm{Nm})$ & $191 \pm 5$ & $218 \pm 36$ & $\mathrm{NS}$ \\
Left knee extension (Nm) & $188 \pm 35$ & $207 \pm 26$ & NS \\
Right knee H/Q ratio (\%) & $58 \pm 9$ & $57 \pm 6$ & NS \\
Left knee H/Q ratio (\%) & $58 \pm 7$ & $56 \pm 8$ & NS \\
\hline
\end{tabular}

NS: no significant differences between groups $(P>0.05)$; G1: long distancerunning athletes without anterior cruciate ligament (ACL) laxity; G2: long distance-running athletes with anterior cruciate ligament (ACL) laxity

Among the 9 athletes with ACL laxity, 5 exhibited laxity in only 1 knee and 4 in both. By evaluating the G2 athletes, we observed that the knee flexion and extension isokinetic peak torque values did not differ statistically from the values obtained in the ACL free knees. No significantly different values were identified in the H/Q ratio between the right and left knees of the G2 athletes. No significant differences were found regarding flexion and extension isokinetic peak torque of the knees in the comparisons drawn between G1 and G2. No significant differences in the H/Q ratio values between the groups were identified.

\section{DISCUSSION}

The isokinetic test provides quantitative information regarding flexion and extension torque of the knees. It has been recently used to analyze the evolution of total knee arthroplasty of elderly patients. ${ }^{24}$ The H/Q ratio shows the equilibrium condition among the forces which act on the knee. There is evidence that a $\mathrm{H} / \mathrm{Q}$ ratio below $60 \%$ is related to ACL injury. ${ }^{25-27}$ However, a small number of studies have focused on the H/Q ratio in running athletes relative to ACL laxity. ${ }^{4,27}$ In the present study, no significant differences were found between the peak torque of the flexors and extensor of the knees or the H/Q ratio between the 2 groups of athletes. The H/Q ratio values of the long distance runners in this study were slightly below the recommended values..$^{25,26}$

Available published information shows relatively lower H/Q ratio data compared to the ones obtained from our long distance runners. The endurance-running athletes in a study performed by Comeau et $\mathrm{a}^{27}$ displayed a $50 \% \mathrm{H} / \mathrm{Q}$ ratio in the right knee and 55\% in the left knee. Siqueira et al ${ }^{4}$ found $\mathrm{H} / \mathrm{Q}$ ratio values of fast runners to be between $56 \%$ and $57 \%$, respectively. Rosene et $\mathrm{al}^{28}$ found much lower $\mathrm{H} /$ Q ratios in soccer (52.5\% and $47.2 \%)$, softball (46.6\% and $46.6 \%$ ), volleyball (50.8\% and $52.4 \%$ ), and basketball players $(55.0 \%$ and $51.2 \%)$. The studies mentioned above did not evaluate the influence of ACL laxity in the H/Q ratio. Ergun et $\mathrm{al}^{29}$ evaluated soccer players and did not find any relation between ACL laxity and the H/Q ratio. These findings combined with ours suggest that the imbalance of the flexor and extensor forces of the knee (H/Q ratio) is not affected whether in the presence of ACL laxity or not. Nevertheless, it does not mean that the risk of ACL injury is not increased in the athletes displaying ligament laxity. ${ }^{10}$

In conclusion, anterior cruciate ligament laxity, evaluated by the Lachman and anterior drawer tests, did not negatively influence the peak torque of the flexor and extensor muscles or the H/Q ratio of the endurance-running athletes. From our data, we reject the hypothesis that ACL laxity negatively affects peak torque and the H/Q ratio of knees in long distance-running athletes. Further, we suggest other studies to evaluate whether there is a higher risk of ACL injury in athletes with ACL laxity.

\section{ACKNOWLEDGMENTS}

The authors thank all the athletes from the "Centro Esportivo e de Lazer Municipal Joerg Bruder" and "Centro Universitário Adventista de São Paulo - UNASP - Campus São Paulo" who participated in this research study. We thank the coaches - Edvaldo Fonseca de Andrade e Advaldo Silva - and the technical teams from UNICID and from the UNASP Physiology Exercise Laboratory. Special thanks are due to Nutrilevi's, for financial support, and to Ayalon Negreli, for revision of language and style. 
Portes EM, Portes LA, Botelho VG, Pinto S de S. Pico de torque isocinético e relação ísquios-tibiais/quadríceps em atletas de endurance com frouxidão do ligamento cruzado anterior. Clinics. 2007;62(2):127-32.

OBJETIVO: Avaliar o torque e a relação de forças entre ísquios-tibiais/quadríceps dos joelhos de atletas corredores de longas distâncias com e sem frouxidão do ligamento cruzado anterior.

METODOLOGIA: Vinte e oito atletas do gênero masculino, 19 sem frouxidão do ligamento cruzado anterior e 9 com frouxidão do ligamento cruzado anterior foram avaliados com aparelho isocinético modelo Cybex 770 . Comparou-se o pico de torque dos quadríceps e dos ísquiostibiais e a relação ísquios-tibiais/quadríceps na velocidade angular constante de $60^{\circ}$ por segundo. Os dados obtidos foram comparados por meio dos testes $t$ de Student e para dados pareados (membros direito e esquerdo) e o nível de significância estabelecido foi $\mathrm{p}<0,05$.

RESULTADOS: Nos atletas com frouxidão do ligamento cruzado anterior os valores de pico de torque (joelhos direito e esquerdo) dos flexores $(120 \pm 15 \mathrm{Nm}$ e $116 \pm 15$ $\mathrm{Nm})$ e dos extensores $(218 \pm 36 \mathrm{Nm}$ e $207 \pm 26 \mathrm{Nm})$ não diferiram significantemente dos atletas sem frouxidão (109 $\pm 21 \mathrm{Nm}$ e $111 \pm 22 \mathrm{Nm} ; 191 \pm 5 \mathrm{Nm}$ e $188 \pm 35 \mathrm{Nm})$. A relação ísquios-tibiais/quadríceps dos atletas com frouxidão ( $57 \pm 6 \%$ e $56 \pm 8 \%)$ também não diferiu daqueles sem frouxidão do ligamento cruzado anterior $(58 \pm 9 \%$ e $58 \pm$ $7 \%)$.

CONCLUSÕES: A frouxidão do ligamento cruzado anterior não alterou significantemente o pico de torque dos flexores e extensores e a relação ísquios-tibiais/quadríceps dos joelhos de atletas corredores de longas distâncias.

UNITERMOS: Torque Isocinético. Joelho. Ligamento Cruzado Anterior. Frouxidão. Atletas.

\section{REFERENCES}

1. Dvir Z. Isocinética: avaliações musculares, interpretações e aplicações clínicas. São Paulo: Manole; 2002. p.201.

2. Foss, ML, Keteyian, SJ. FOX Bases fisiológicas do exercício e do esporte. 6a ed. São Paulo: Guanabara Koogan; 2000. p.560.

3. Ahmad CS, Clark M, Heilmann N, Schoeb S, Gardner TR, Levine WN. Effect of gender and maturity on quadriceps-to-hamstring strength ratio and anterior cruciate ligament laxity. Am J Sports Med. 2005;34:1-5.

4. Siqueira CM, Pelegrini FR, Fontana MF, Greve JD. Isokinetic dynamometry of knee flexors and extensors: comparative study among non-athletes, jumper athletes and runner athletes. Rev Hosp Clin Fac Med Sao Paulo. 2002; 57(1):19-24.

5. Hewett TE, Myer GD, Ford KR. Prevention of anterior cruciate ligament injuries. Curr Womens Health Rep. 2001;1:218-24.

6. Grace TG, Sweetser ER, Nelson MA, Ydens LR, Skipper BJ. Isokinetic muscle imbalance and knee-joint injuries. A prospective blind study. J Bone Joint Surg Am. 1984;66:734-40.

7. Aagaard P, Simonsen EB, Trolle M, Bangsbo J, Klausen K. Isokinetic hamstring/quadriceps strength ratio: influence from joint angular velocity, gravity correction and contraction mode. Acta Physiol Scand. 1995;154:421-7.

8. Aagaard P, Simonsen EB, Magnusson SP, Larsson B, Poulsen PD. A new concept for isokinetic hamstring: quadriceps muscle strength ratio. Am J Sports Med. 1998;26:231-7.

9. Devan MR, Pescatello LS, Faghri P, Anderson J. A prospective study of overuse knee injuries among female athletes with muscle imbalances and structural abnormalities. J Athl Train. 2004;39:263-7.
10. Baratta R, Solomonow M, Zhou BH, Letson D, Chuinard R, D’Ambrosia R. Muscular coactivation. The role of the antagonist musculature in maintaining knee stability. Am J Sports Med. 1988;16:113-22.

11. Logan MC, Williams A, Lavelle J, Gedroyc W, Freeman M. What really happens during the lachman test? A dynamic MRI analysis of tibiofemoral motion. Am J Sports Med. 2004;32:369-75.

12. Li RC, Maffulli N, Hsu YC, Chan KM. Isokinetic strength of the quadriceps and hamstrings and functional ability of anterior cruciate deficient knees in recreational athletes. Br J Sports Med. 1996;30:1614.

13. Boyle KL, Witt P, Riegger-Krugh C. Intrarater and interrater reliability of the beighton and horan joint mobility index. J Athl Train. 2003;38:281-5.

14. Hurley LW, McGuire TD. Influences of clinician technique on performance and interpretation of the Lachman test. J Athl Train. 2003;38:34-43.

15. Stewart DR, Burden SB. Does generalized ligamentous laxity increase seasonal incidence of injuries in male first division club rugby players? Br J Sports Med. 2004;38:457-60.

16. Inklaar H. Soccer injuries. II. Aetiology and prevention. Sports Med. 1994;18:81-93.

17. Nicholas JA. Injuries to knee ligaments: relationship to looseness and tightness in football players. JAMA. 1970; 212:2236-9.

18. ACSM's Guidelines for exercise testing and prescription. 5th ed. Philadelphia: Williams and Wilkins; 1995. p.373. 
19. Eston R, Reilly T. Kinanthropometry and exercise physiology laboratory manual: tests, procedures and data. 2nd ed. New York: Routledge; 2001.p.301.

20. Heyward VH. Advanced fitness assessment and exercise prescription. 4th ed. Champaign: Human Kinetics; 2002. p.367.

21. Scholten RJ, Opstelten W, Plas CGV, Bijl D, Deville WL, Bouter LM. Accuracy of physical diagnostic tests for assessing ruptures of the anterior cruciate ligament: a meta-analysis. J Fam Pract. 2003;52:68994.

22. Jackson JL, O'Malley PG, Kroenke K. Evaluation of acute knee pain in primary care. Ann Intern Med. 2003;139:575-88.

23. Egri D, Yoshinari NH. Hipermobilidade articular generalizada. Rev Bras Reumatol. 1999;39:231-6.

24. Aquino MA, Leme LEG. Isokinetic dynamometry in elderly women undergoing total knee arthroplasty: a comparative study. Clinics. 2006;61:215-222.
25. Ghena D, Kurth AL, Thomas M. Moment characteristics of the quadriceps and hamstring muscles during concentric and eccentric loading. J Orthop Sports Phys Ther. 1991;14:149-54.

26. MacLean CL, Taunton JE, Clement DB, Regan W. Eccentric and concentric isokinetic moment characteristics in the quadriceps and hamstrings of the chronic isolated posterior cruciate ligament injured knee. Br J Sports Med. 1999;33:405-8.

27 Comeau MJ, Zebas C, Brown LE, Greenwood M, Greenwood L. The hamstring/quadriceps ratio of male endurance runners over a velocity spectrum. Med Sci Sports Exerc. 2001;33:S333.

28. Rosene JM, Fogarty TD, Mahaffey BL. Isokinetic hamstrings:quadriceps ratios in Intercollegiate athletes. J Athl Train. 2001;36:378-83.

29. Ergun M, Islegen C, Taskiran E. A cross-sectional analysis of sagittal knee laxity and isokinetic muscle strength in soccer players. Int J Sports Med. 2004;25:594-8. 